\title{
Development of a NiTi Anterior Cruciate Ligament Prosthesis
}

\author{
N. Hagemeister, L'H. Yahia and T. Lours* \\ Biomedical Engineering Institute, Ecole Polytechnique, C.P. 6079, Succ. "Centre Ville", Montréal, \\ H3C 3A7, Québec, Canada \\ * Imago Canada, 9557 Côte de Liesse, Dorval, H9P 1A3, Québec, Canada
}

\begin{abstract}
For the development of a Shape Memory Alloy (SMA) ligament prosthesis model, it is necessary to overcome the problem of the fatigue life under mechanical loading of nickel titanium wires. The degradation of the superelastic parameters as a function of the cyclic strain was evaluated and the number of cycles to failure under controled strain was established. On the basis of these results, an orientation in the design of the SMA ligament prosthesis can be proposed.
\end{abstract}

\section{INTRODUCTION}

Anterior cruciate ligament injuries can cause instability or abnormal movement of the knee joint that may result in femoro-tibial arthrosis. This fact leeds the surgeons to develop systems for the reconstruction of the knee ligament. None of the prostheses presently at study or available on the market presents satisfactory clinical results.

A previous study [1] evaluated most of the recent designs available on the market or at study, their structure, mechanical properties, fatigue life and clinical results (when available). These characteristics have been compared to those of the natural ligament. Problems are mostly:

- a too high stiffness of the material resulting in a low elastic strain,

- an important wear at the insertion tunnels. A poor resistance lead to wear debris and are responsible for the foreign body reaction and could lead to cartilage destruction.

- a short fatigue life due to physiological combined loading and a poor resistance of the materials to high constraints.

The most important mechanical parameters for the ligament prosthesis are its maximal elastic strain, its elastic modulus, its maximal load to failure and its fatigue life under combined loading $[1,2]$.

Based on a study by Yahia et al.[1], which relates the structural, physiological, biomechanical and surgical conditions to be respected in the development of a ligament prosthesis, the design criteria for tha development of a new generation of nickel titanium (NiTi) Shape Memory ligament prosthesis was established (table I). We focused more specifically on the problem of selection of the material and on the evaluation of its fatigue life. This preliminary study will allow us to define the limit of use of this material and to propose a design. 
Table I: Design criteria for the development of a NiTi ligament prosthesis

\begin{tabular}{|c|c|c|c|}
\hline \multirow{4}{*}{$\begin{array}{c}\text { ANATOMICAL } \\
\text { CHARACTERISTICS }\end{array}$} & & NATUREL LCA & $\begin{array}{l}\text { SHAPE MEMORY } \\
\text { LIGAMENT } \\
\text { PROSTHESIS }\end{array}$ \\
\hline & Shape & $\begin{array}{l}\text { flared, several } \\
\text { functional bands }\end{array}$ & $\begin{array}{l}\text { At least two fonctional } \\
\text { bands }\end{array}$ \\
\hline & Dimension. & $\begin{array}{l}\text { Mean section : } \pm 90 \mathrm{~mm}^{2} \\
\text { Insertion Surfaces } \\
\text { Tibia: } \pm 135 \mathrm{~mm}^{2} \\
\text { Femur: } \pm 115 \mathrm{~mm}^{2}\end{array}$ & $\begin{array}{l}\text { Maximal section surface: } \\
\pm 100 \mathrm{~mm}^{2}\end{array}$ \\
\hline & Fixation & $\begin{array}{l}\text { Rigidity increases } \\
\text { between the ligament } \\
\text { and the bone [3] }\end{array}$ & $\begin{array}{l}\text { - Avoid sharp angles } \\
\text { between prosthesis and } \\
\text { bone tunnels. } \\
\text { - Rigid fixation to avoid } \\
\text { mouvement in the bone } \\
\text { tunnels }\end{array}$ \\
\hline \multirow{5}{*}{$\begin{array}{l}\text { BIOMECHANICAL } \\
\text { CHARACTERISTICS }\end{array}$} & $\begin{array}{l}\text { Mechanical } \\
\text { solicitation }\end{array}$ & $\begin{array}{l}\text { Combined loading in } \\
\text { torsion, tension and } \\
\text { flexion [4] }\end{array}$ & $\begin{array}{l}\text { Must be able to support } \\
\text { combined loading }\end{array}$ \\
\hline & Maximal force & $1730 \mathrm{~N}$ & $3000 \mathrm{~N}$ \\
\hline & $\begin{array}{l}\text { Reversible } \\
\text { deformation }\end{array}$ & $20-25 \%$ & $10-15 \%$ \\
\hline & $\begin{array}{l}\text { Maximal } \\
\text { deformation }\end{array}$ & $30-35 \%$ & $30-35 \%$ \\
\hline & Rigidify & $180 \mathrm{~N} / \mathrm{mm}$ & $180 \mathrm{~N} / \mathrm{mm}$ \\
\hline
\end{tabular}

\section{WHY USING SHAPE MEMORY ALLOYS?}

\subsection{The superelastic property of NiTi}

Thanks to its superelastic property, NiTi can sustain great strains without residual strain. Furthermore, by using the superelastic plateau of the wire, it is possible to obtain an important strain and controlled stress as soon as the critical stress of stress induced martensite is reached. It is nervertheless important to obtain a good fatigue life because the prosthesis in vivo will be cycled in combined loading about 40 Million times in 15 years.

\subsection{The shape memory property of NiTi}

Knowing its fairly good biocompatibility, NiTi shape memory alloys have been used for orthopaedic applications, especially for osteosynthesis, scoliosis correction systems etc... [5,6]. The Shape Memory property is extremely usefull in these cases, because the implantation is made easier. All devices are placed in a deformed state in cool conditions, and, once in place, they are heated up at body temperature. The reverse martensitic transformation will then lead the alloy to recover its shape, and perform its role. In the case of the ligament prosthesis, the same technique will be used. 


\subsection{The mechanical behavior of NiTi}

The thermomechanical characteristics of NiTi give the possibility to reproduce the mechanical behavior of the natural anterior cruciate ligament better that other materials. In fact, this material presents on one side the stress hysteresis, and on the other side the minimal reversible deformation for a great strain.

\section{CHOICE OF THE MATERIAL AND OPTIMIZATION OF ITS THERMO-MECHANICAL BEHAVIOUR}

The alloy is a nearly equiatomic NiTi. The specimen are wires $0.2 \mathrm{~mm}$ in diameter and $180 \mathrm{~mm}$ in length with $30 \mathrm{~mm}$ between gripping. In order ro reduce stress concentration at the grips, we developed special grips for the fatigue tests [7]. The wires have been heat treated at $525^{\circ} \mathrm{C}$ for 10 minutes. Several heat treatments have been foreseen [7]. An optimal heat treatment give us a superelastic behaviour without inducing permanent strain of the austenitic phase and activates minimal surface oxidation. The transformation temperatures have been measured by Differential Scanning Calorimetry (DSC): $A_{f}=10^{\circ} \mathrm{C} ; A_{s}=-5^{\circ} \mathrm{C} ; M_{s}=-22^{\circ} \mathrm{C} ; \mathrm{M}_{\mathrm{f}}=-39^{\circ} \mathrm{C}$.

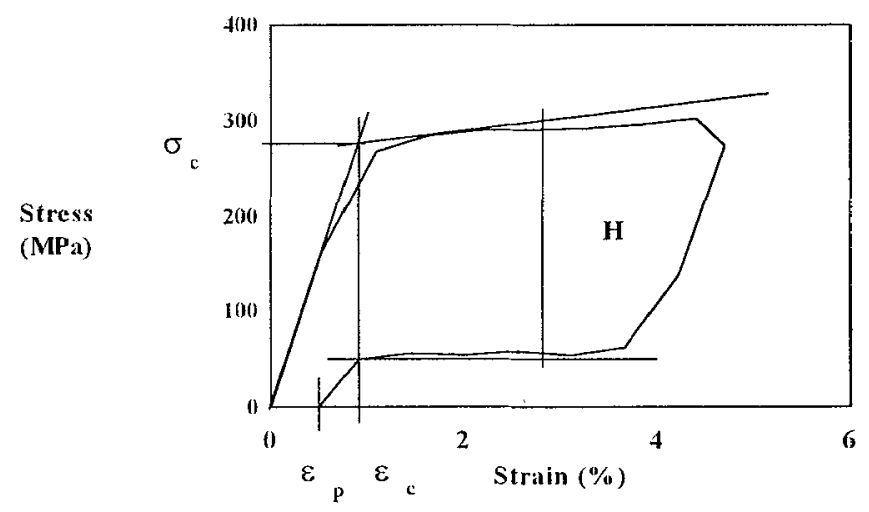

Figure 1: Stress-strain curve of the NiTi wire. The superelastic parameters are:

$\sigma_{c}=$ critical stress of stress induced martensite $\epsilon_{\mathrm{p}}=$ plastic strain

$\epsilon_{\mathfrak{c}}=$ critical strain of stress induced martensite $\mathrm{H}=$ hysteresis

\section{FATIGUE BEHAVIOR}

It is important to characterize the fatigue life of the wires and to determine a range of strain in which the superelastic behavior of NiTi is stable. Therefore, we first performed cyclic tension tests which gave us the variation of the superelastic parameters $\sigma_{c}, \epsilon_{c}, \epsilon_{\mathrm{p}}$ and $\mathrm{H}$ as a function of numbers of cycles, as described in figure 1. Fatigue tests have been performed on a hydraulic Material Testing System (MTS) BIONIX machine, stress was measured by a load cell and strain by an LVDT. Every $10,20,30,50,100,200,300,500,1000$ and 3000 th cycle a stress-strain curve has been drawn and superelastic parameters have been noted. Strain rate was $1 \% / \mathrm{min}$, frequency of cycling was $5 \mathrm{~Hz}$ and test temperature was $25^{\circ} \mathrm{C}$. Second, the fatigue life of the NiTi wires at controlled strain, for different strain amplitudes was evaluated. A $\epsilon-\mathrm{N}$ curve gives us the fatigue life as a function of number of cycles. Fatigue tests have been performed in controlled strain because the natural ligament is cycled under controlled strain. 


\subsection{Results and discussion}

\subsubsection{Variation of the superelastic paramerers}

The following curves give us the evolution of the superelastic parameters as a function of number of cycles for different cyclic strains (figure 2, 3 and 4). The curves have been drawn for 2, 3, 4 and $5 \%$ cyclic strain and the mean value of two essais has been noted.

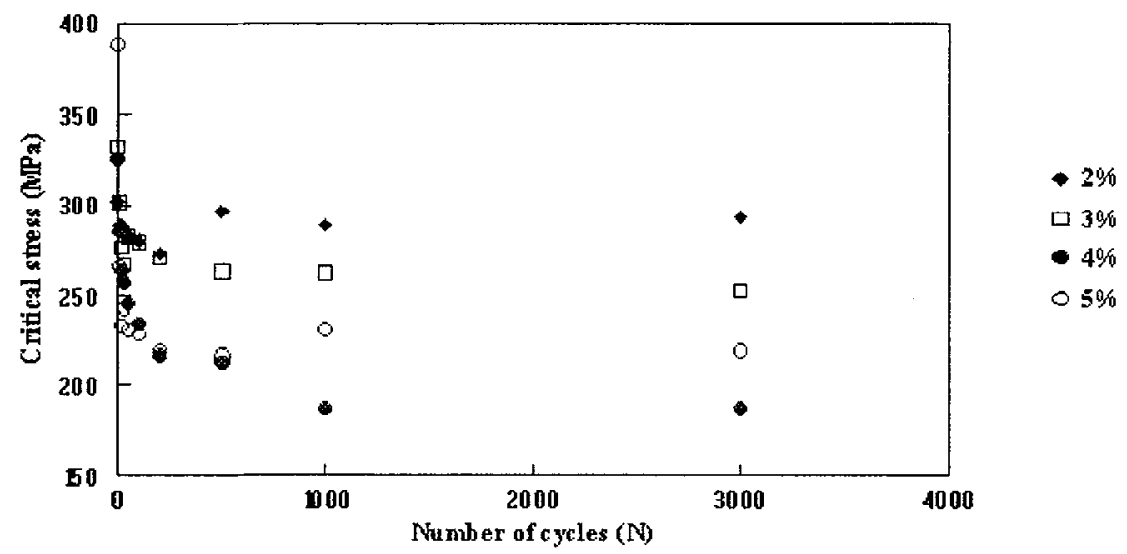

Figure 2: Variation of the critical stress of stress induced martensite as a function of number of cycles for different cyclic strains.

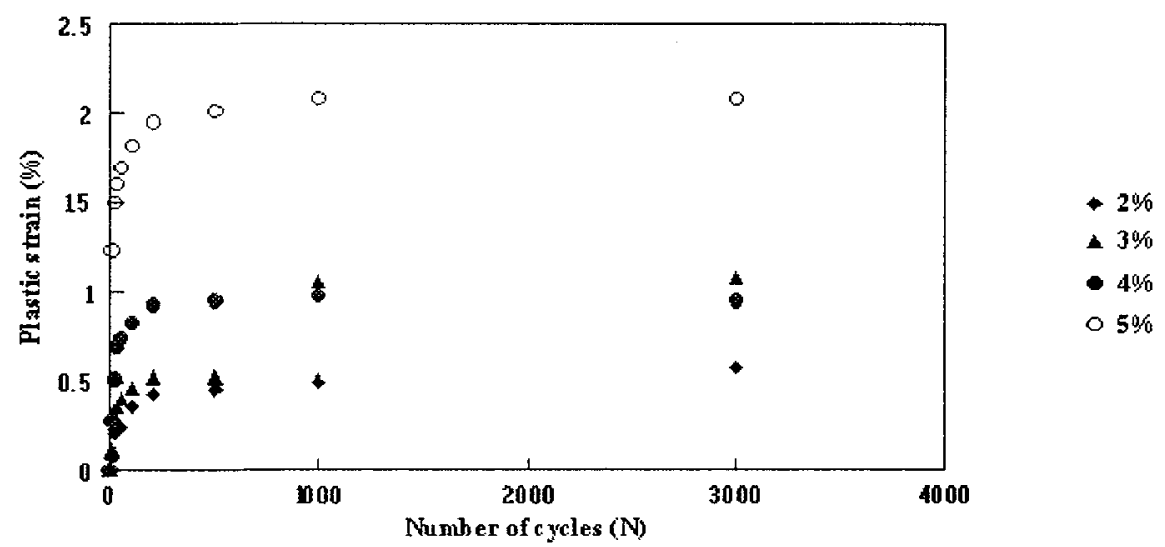

Figure 3: Variation of the plastic strain as a function of number of cycles for different cyclic strains. 


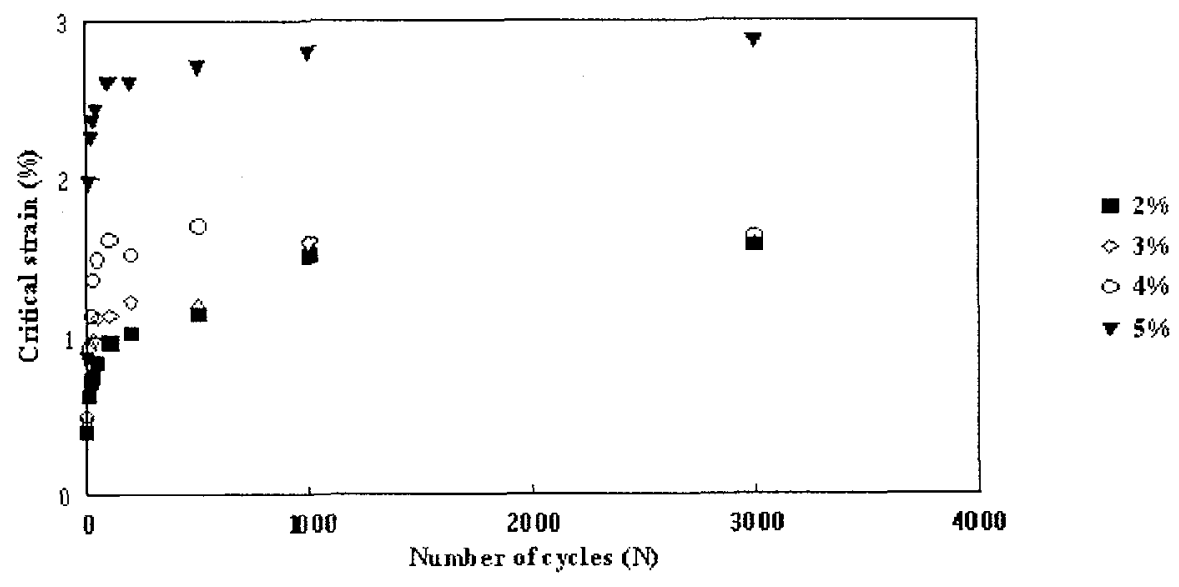

Figure 4: Variation of the critical strain as a function of number of cycles for different cyclic strains.

After about 100 cycles, a stabilization of the superelastic parameters was observed. Therefore, we can assume that the NiTi prosthesis will show a stable behaviour if it is pre-cycled before implantation. The mechanism of degradation depends of the cyclic strain. In fact, for $5 \%$ cyclic strain, we observe more degradation, than for the other cyclic strains. This is due to the fact that at every cycle at $5 \%$ strain, a plastification of the parent phase takes place. This phenomenon lowers the critical stress for starting stress induced martensite and increases the plastic deformation.

\subsection{2. $\epsilon-N$ curve}

The fatigue life of NiTi wires was evaluated by cycling them at different strains until rupture was observed. Figure 5 shows the number of cycles until rupture as a function of cyclic deformation. Cycling took place at a frequency of $5 \mathrm{~Hz}$ at room temperature. Each point on the curve corresponds to a mean of 5 tests.

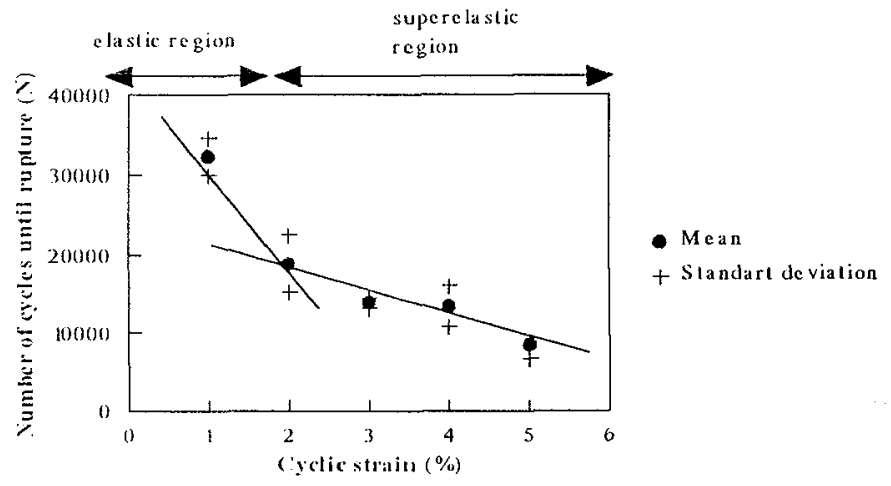

Figure 5: Number of cycles until rupture as a function of cyclic deformation 
Figure 5 shows that the fatigue life can be devided in two regions: an elastic region (up to $2 \%$ strain), where the specimen is cycled only in the elastic part of the parent phase, and a superelastic region, where, at each cycle, the specimen undergoes a martensitic transformation. The elastic region corresponds to a better fatigue life (20 000 cycles) than the superelastic region. The mechanical cycling must take place in the martensitic transformation region in order to be able to reproduce the mechanical behavior of the natural ligament. The results do not satisfy the demands of the ligament prosthesis:

- The fatigue life time is too low compared to that imposed by the design criteria

- In order to obtain a longer fatigue life, we can not use the wire in its superelastic regime

This study gave us a better understanding of the fatigue properties and mechanisms of NiTi wires. Nevertheless, the wire geometry does not permit a sufficiant large strain range for a good fatigue life and therefore, it is not usable for the prosthetic application.

Now, the advantage of using Shape Memory Alloys is to reproduce the mechanical behaviour of the natural ligament. This is impossible with other conventional materials. A new orientation in the design of the ligament prosthesis has to be taken. A solution would be to use superelastic springs or helical structures. In fact, these structures are able to undergo large macroscopic deformation while the microscopic strain remains small.

\section{FUTURE WORK}

In order to develop a superelastic Shape Memory Alloy prosthesis, we will investigate the possibility of using NiTi springs. These springs will give us the opportunity to develop a prosthesis with a mechanical behavior close to that of the natural ligament. The next main steps of our work will be to:

- calculate the geometry of the springs in order to satisfy the physiologic dimensions

- calculate the spring parameters (mean diameter, diameter of the wire, nomber of whorls)

- evaluate the fatigue life with cyclic tension tests

- perform clinical trials

\section{ACKNOWLEDGEMENTS}

The authors would like to thank Imago Canada for technical and financial support.

\section{REFERENCES}

[1] Yahia, L'H., Hagemeister, N., Drouin, G., Sati, M., Rivard, C.H., Biomimetics (1994) In press.

[2] Jenny, J.Y., Jenny, G., Daubesse, F., International Orthopaedics (SICOT) 15(1991) 23-28.

[3] Sepulchre, P., Blaimont, P., Acta Orthopaedica Belgica 53(3) (1987) 331-337.

[4] Drouin, G., Gely, P., Tiberghien, M., Tremblay, G.R., 17th Annual Meeting of the Canadian Orthopaedic Society, Québec, June 1983.

[5] Haasters, J., In: Engeneering Aspects of Shape Memory Alloys, T.W. Duerig, K.N. Melton (Butterworth-Heinemann, 1990) pp.427-443.

[6] Sanders, M., Coole, J., Veldhuizen, A., International Symposium on 3D Scoliotic Deformities (J. Dansereau ed., 1992) pp.343-350.

[7] Hagemeister, N., Yahia, L'H., Armand, C., Lours, T., SMST Conference, Asilomar, California, 6 March 1994. 